\title{
Phylogenetic Diversity of Archaea and the Archaeal Ammonia Monooxygenase Gene in Uranium Mining-Impacted Locations in Bulgaria
}

\author{
Galina Radeva, ${ }^{1,2}$ Anelia Kenarova, ${ }^{3}$ Velina Bachvarova, ${ }^{2}$ Katrin Flemming, ${ }^{1}$ Ivan Popov, \\ Dimitar Vassilev, ${ }^{5}$ and Sonja Selenska-Pobell ${ }^{1}$ \\ ${ }^{1}$ Helmholtz-Centre Dresden-Rossendorf, Institute of Resource Ecology, Bautzner Landstraße 400, 01328 Dresden, Germany \\ ${ }^{2}$ Institute of Molecular Biology, Bulgarian Academy of Sciences, Academic G. Bonchev Street, Building 21, 1113 Sofia, Bulgaria \\ ${ }^{3}$ Faculty of Biology, Sofia University, 8 Dragan Tsankov Boulevard, 1164 Sofia, Bulgaria \\ ${ }^{4}$ Molecular Medicine Centre, Medical University of Sofia, 1 Georgy Sofiiski Street, 1431 Sofia, Bulgaria \\ ${ }^{5}$ Agrobioinstitute, 8 Dragan Tsankov Boulevard, 1164 Sofia, Bulgaria
}

Correspondence should be addressed to Galina Radeva; gradeva@bio21.bas.bg

Received 29 November 2013; Accepted 17 January 2014; Published 11 March 2014

Academic Editor: William B. Whitman

Copyright (C) 2014 Galina Radeva et al. This is an open access article distributed under the Creative Commons Attribution License, which permits unrestricted use, distribution, and reproduction in any medium, provided the original work is properly cited.

\begin{abstract}
Uranium mining and milling activities adversely affect the microbial populations of impacted sites. The negative effects of uranium on soil bacteria and fungi are well studied, but little is known about the effects of radionuclides and heavy metals on archaea. The composition and diversity of archaeal communities inhabiting the waste pile of the Sliven uranium mine and the soil of the Buhovo uranium mine were investigated using 16S rRNA gene retrieval. A total of 355 archaeal clones were selected, and their 16S rDNA inserts were analysed by restriction fragment length polymorphism (RFLP) discriminating 14 different RFLP types. All evaluated archaeal 16S rRNA gene sequences belong to the 1.1b/Nitrososphaera cluster of Crenarchaeota. The composition of the archaeal community is distinct for each site of interest and dependent on environmental characteristics, including pollution levels. Since the members of 1.1b/Nitrososphaera cluster have been implicated in the nitrogen cycle, the archaeal communities from these sites were probed for the presence of the ammonia monooxygenase gene (amoA). Our data indicate that amoA gene sequences are distributed in a similar manner as in Crenarchaeota, suggesting that archaeal nitrification processes in uranium mining-impacted locations are under the control of the same key factors controlling archaeal diversity.
\end{abstract}

\section{Introduction}

Metagenomic studies have revealed that Archaea are widely distributed and likely play an important role in a variety of environmental processes, such as chemoautotrophic nitrification [1], carbon metabolism [2], and amino acid uptake [3, 4]. The most abundant organisms among the archaeal phyla are Crenarchaeota and Euryarchaeota $[2,5]$. Crenarchaeota represent more than $75 \%$ of the archaeal populations in natural environments [6]. Certain crenarchaeotic groups are thought to be confined to specific environments; for example, group 1.1a consists mainly of aquatic organisms, while the members of group 1.1b are typical soil crenarchaeotes [7].

Worldwide mining and milling activities have introduced high levels of radionuclides and heavy metals (HMs) into soil and aquatic environments. The adverse effects of pollutants on Archaea are not well studied $[8,9]$. Moreover, only a few studies have investigated archaeal diversity in HM- $[10,11]$ and uranium- (U-) contaminated environments [5, 12-14]. Radeva and Selenska-Pobell [13] reported crenarchaeotic 16S rRNA gene sequences in U-contaminated soils of Saxony, Germany, belonging only to the $1.1 \mathrm{~b}$ group of the phyla, while Reitz et al. [14] identified 1.1a, 1.3b, and SAGMCG.1 crenarchaeotic gene sequences from deeper U-polluted soil horizons. Porat et al. [5] investigated the diversity of archaeal communities from mercury- and U-contaminated freshwater stream sediments by pyrosequencing analysis. They found a higher abundance and diversity of Archaea in mercury- than in U-contaminated sites, where the archaeal sequences were of both the Crenarchaeota and Euryarchaeota phyla. 
To date, little is known concerning the interactions between archaea and U or HMs. Kashefi et al. [15] published that the hyperthermophilic crenarchaeote Pyrobaculum islandicum is able to reduce $\mathrm{U}(\mathrm{VI})$ to $\mathrm{U}(\mathrm{IV})$ under anaerobic conditions at $100^{\circ} \mathrm{C}$. Francis et al. [16] demonstrated that the halophilic euryarchaeote Halobacterium halobium accumulates high amounts of $\mathrm{U}(\mathrm{VI})$ as extracellular uranyl phosphate deposits; however, these two organisms are not found in U-contaminated substrata. Later, Reitz et al. $[9,17]$ revealed the capacity of the acidothermophilic Sulfolobus acidocaldarius, which is an indigenous archaeon for $\mathrm{U}$ contaminated soils and mine tailings, to accumulated intracellular U(VI).

The discovery that some mesophilic archaea from Crenarchaeota, which were later categorized into the new Thaumarchaeota phylum [18], have the potential to oxidize ammonia suggests an important role of archaea in the nitrogen $(\mathrm{N})$ cycle $[19,20]$. The crenarchaeotic ammonia monooxygenase gene $(a m o \mathrm{~A})$ is found in many natural environments, such as soil [2, 21], marine, and freshwater ecosystems [22-25], several geothermal environments and hot springs [26-28], Artic lakes [29], drinking water production plants [30], and wastewater treatment plants [31]. This widespread distribution indicates the ubiquity and significance of archaeal ammonia oxidizers in the global $\mathrm{N}$ cycle [21, 32-34]. However, there are few studies assessing the abundance of archaeal amo $\mathrm{A}$ and its diversity in $\mathrm{U}$-impacted environments.

Intensive $\mathrm{U}$ mining and milling in Bulgaria were performed between 1946 and 1990 and have caused significant soil and water pollution. U production was stopped by a government decree in 1992, and mines and tailings were technically liquidated and gradually remediated. Nevertheless, their surroundings are still highly contaminated, and further contamination from the compromised remediation of mines and tailings has been recorded.

The aim of this study was to investigate the diversity of archaeal communities inhabiting environments impacted by $\mathrm{U}$ mining and milling activities and in particular to reveal the diversity of the archaeal amoA gene. Since U and HM contamination represent an old environmental burden, we expected that the composition and diversity of archaeal and amoA communities were stabilized under the selective power of both contamination level and environmental characteristics.

\section{Materials and Methods}

2.1. Sites and Sampling. Two locations in Bulgaria were studied: the abandoned mining and milling complex "Buhovo" and the "Sliven" mine, both of which have been classified as areas of high radiological risk by the Bulgarian Agency for Radiobiology and Radioprotection. The mining complex "Buhovo" ( $\left.42^{\circ} 45^{\prime} 51.20^{\prime \prime} \mathrm{N} ; 23^{\circ} 34^{\prime} 36.86^{\prime \prime} \mathrm{E}\right)$ is located $30 \mathrm{~km}$ northeast of Sofia on a 2,280 ha territory, while the "Sliven" mine $\left(42^{\circ} 41^{\prime} 47.68^{\prime \prime} \mathrm{N} ; 26^{\circ} 22^{\prime} 22.47^{\prime \prime} \mathrm{E}\right)$ is located in South Eastern Bulgaria and occupies an area of 491 ha (Figure 1). Mining operations at the two locations were conducted in a conventional underground manner from 1962 to 1981. They were officially closed in 1992 and remediated until 2001.

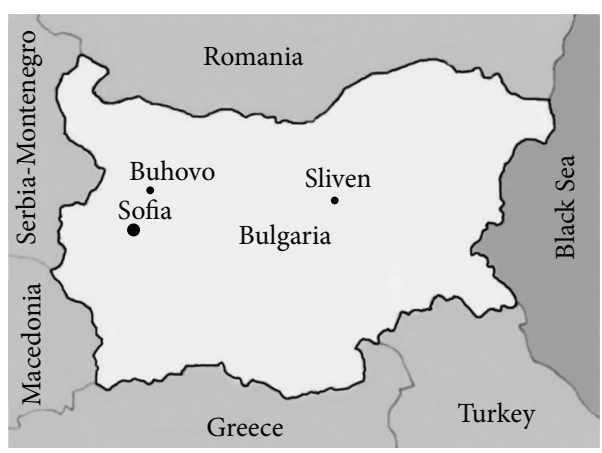

FIgURE 1: Map of Bulgaria and the location of the studied sites Buhovo (BuhC and BuhD) and Sliven (Sliv).

Samples from Buhovo were collected in May 2003 at depths of $20 \mathrm{~cm}$ (BuhC) and $40 \mathrm{~cm}$ (BuhD). Samples labelled "Sliv" were collected in June 2004 from the "Sliven" mine waste pile at a depth of $40 \mathrm{~cm}$. Five samples from BuhC, BuhD, and Sliv were collected under sterile conditions, transported at $4^{\circ} \mathrm{C}$, and stored at $-20^{\circ} \mathrm{C}$ until use.

2.2. Environmental Variables. The organic matter content of the sample was determined by Turyn's method based on its oxidation by potassium dichromate [35]. The $\mathrm{pH}$ was measured using a portable potentiometer (HANA pH meter) after the soil samples had been suspended in distilled water (soil: liquid, $1: 2.5$ ). The concentrations of sulfates and nitrates were determined using a spectrophotometer in $0.1 \mathrm{M} \mathrm{CaCl}_{2}$ soil extract following methods described by Bertolacini and Barney II [36] and Keeney and Nelson [37], respectively. The concentration of HMs was measured using an ELAN 5000 Inductively Coupled Plasma Mass Spectrometer (Perkin Elmer, Shelton, CT, USA) in a $1 \mathrm{M} \mathrm{HCl}$ solution $(1: 20$; soil $: 1 \mathrm{M} \mathrm{HCl})$. The results were calculated for oven-dried soil.

2.3. DNA Extraction. Total DNA ( $>25 \mathrm{~kb}$ ) was extracted from the samples (3g) after direct lysis using the method described by Selenska-Pobell et al. [38], and the DNA subsamples (five DNA subsamples for sampling site) were collected in a representative average sample for further analysis.

2.4. PCR Amplification. Archaeal $16 \mathrm{~S}$ rRNA genes from the genomic DNA were amplified via seminested PCR using specific archaeal $16 \mathrm{~S}_{21-40 \mathrm{~F}}\left(5^{\prime}\right.$-TTCCGGTTGATCCYGCCGGA-3 $\left.{ }^{\prime}\right)$ and universal $16 \mathrm{~S}_{1492-1513 \mathrm{R}}\left(5^{\prime}\right.$-ACGGYTACCTTGTTACGACTT- $3^{\prime}$ ) primers. Each PCR reaction mixture $(20 \mu \mathrm{L})$ contained $200 \mu \mathrm{M}$ deoxynucleotide triphosphates, $1.25 \mathrm{mM} \mathrm{MgCl}_{2}, 1.25 \mathrm{mM} \mathrm{MgCl}_{2}, 10$ pmol DNA primers, 15 ng template DNA, and $1 \mathrm{U}$ AmpliTaq Gold polymerase with the corresponding 10x buffer (Perkin Elmer, Foster City, CA, USA). The amplifications were performed with a "touch down" PCR in a thermal cycler (Biometra, Göttingen, Germany). After an initial denaturation at $94^{\circ} \mathrm{C}$ for $7 \mathrm{~min}$, the annealing temperature was decreased from 59 to $55^{\circ} \mathrm{C}$ over five cycles, followed by 25 cycles each with a profile 
of denaturation at $94^{\circ} \mathrm{C}(60 \mathrm{sec}), 55^{\circ} \mathrm{C}(40 \mathrm{sec})$, and $72^{\circ} \mathrm{C}$ $(90 \mathrm{sec})$. The amplification was completed by an extension of $20 \mathrm{~min}$ at $72^{\circ} \mathrm{C}$. The diluted products of the first reaction were used as templates for the second round of PCR, where two archaeal specific primers $16 \mathrm{~S}_{21-40 \mathrm{~F}}$ and $16 \mathrm{~S}_{940-958 \mathrm{R}}\left(5^{\prime}\right.$-YCCGGCGTTGAMTCCAATT- $3^{\prime}$ ) were applied [39]. The initial denaturation at $95^{\circ} \mathrm{C}$ for $7 \mathrm{~min}$ was followed by 25 cycles each consisting of denaturation at $94^{\circ} \mathrm{C}(60 \mathrm{sec})$, annealing at $60^{\circ} \mathrm{C}(60 \mathrm{sec})$, and polymerization at $72^{\circ} \mathrm{C}(60 \mathrm{sec})$. The amplification was completed by an extension of $10 \mathrm{~min}$ at $72^{\circ} \mathrm{C}$. This seminested PCR format was applied to obtain a sufficient amount of PCR products for the cloning procedure.

Archaeal amoA fragments ( $635 \mathrm{bp})$ were amplified using the PCR primers Arch-amoAF (5' -STAATGGTCTGGCTTAGACG- $3^{\prime}$ ) and Arch-amoAR ( $5^{\prime}$-GCGGCCATCCATCTGTATGT- ${ }^{\prime}$ ) [40]. PCR cycling was conducted according to Francis et al. [40], with an initial denaturation at $95^{\circ} \mathrm{C}$ for 5 min followed by 35 cycles of the following: denaturation at $94^{\circ} \mathrm{C}(45 \mathrm{sec})$, annealing at $53^{\circ} \mathrm{C}(1 \mathrm{~min})$, and extension at $72^{\circ} \mathrm{C}(1 \mathrm{~min})$. Amplification was completed by an extension of $15 \mathrm{~min}$ at $72^{\circ} \mathrm{C}$.

2.5. 16S rRNA Gene Clone Libraries. One archaeal and one amoA gene clone libraries for BuhC, BuhD, and Sliv were constructed using the pooled products from the PCR reactions. The 16S rDNA amplicons from five replicates were combined and cloned directly into Escherichia coli using a TOPO TA Cloning Kit (Invitrogen, Carlsbad, CA, USA) following the manufacturer's instructions to generate clone libraries. The archaeal 16S rRNA gene inserts and amoA gene inserts were subsequently amplified by PCR with plasmid-specific primers for the vectors M13 and M13 rev and then digested $\left(2 \mathrm{~h}, 37^{\circ} \mathrm{C}\right)$ with the MspI and HaeIII restriction enzymes following the manufacturer's instructions (Thermo Fisher Scientific, USA). Restriction fragment length polymorphism (RFLP) patterns were visualized using 3.5\% Small DNA Low Melt agarose gels (Biozym, Hessisch, Oldenburg, Germany), and these data were then used to group clones into phylotypes. The representatives of the RFLP types were purified using an Edge BioSystems Quick-Step 2 PCR Purification Kit (MoBiTec, Gottingen, Germany) and then sequenced using the BigDye Termination v.3.1 Kit (Applied Biosystems) and ABI PRISM 310 DNA sequencer (Applied Biosystems, Foster City, CA, USA). The sequencing of archaeal 16S rRNA gene fragments was performed using the primers $16 \mathrm{~S}_{21-40 \mathrm{~F}}$ and $16 \mathrm{~S}_{940-958 \mathrm{R}}$, while amoA gene fragments were sequenced using the vector primer SP6.

2.6. Phylogenetic Analysis. The sequences obtained were analysed and compared with those in the GenBank database using the BLAST server at the National Centre for Biotechnology Information (NCBI) (http://www.ncbi.nlm.nih.gov). The presence of chimeric sequences in the clone libraries was determined using the programs CHIMERA CHECK, available on the Ribosomal Database Project II (release 11.0) and Bellerophon [41]. The sequences were aligned with those corresponding to the closest phylogenetic relatives using the Clustal W program [42]. Phylogenetic trees were constructed according to the neighbour-joining method using the Bioedit software package.

2.7. Data Analysis. The results were statistically analysed by NCSS97 (NCSS, Kaysville, Utah), and the average values were presented. The sampling efficiency and diversity within the archaeal clone libraries were estimated using the MOTHUR software program based on the furthest-neighbour algorithm, and the sequences were grouped into operational taxonomic units (OTUs) [43] at sequence similarity levels (SSLs) of BuhC $\geq 97 \%$ (0.03 distance), BuhD $\geq 94 \%$ (0.06 distance), and Sliv $\geq 91 \%$ (0.09 distance). For each sample, the archaeal OTU richness (rarefaction curves, Chao 1, ACE) [44] and diversity (Shannon-Weiner index) [45] estimates were calculated. Statistical analysis of amoA OTUs was not carried out because of the low number of unique gene sequences identified in the BuhC, BuhD, and Sliv clone libraries. The level of pollution was expressed using a toxicity index (TI) as follows:

$$
\mathrm{TI}=\frac{\sum C_{i}}{\operatorname{ED} 50_{i}},
$$

where $C_{i}$ is the concentration of metal $i$ in substratum $\left(\mathrm{mg} \mathrm{kg}^{-1}\right)$ and ED50 is the total concentration of metal causing 50\% reduction in microbial dehydrogenase activity (original ED50s were taken from Welp [46]).

2.8. Nucleotide Sequence Accession Numbers. The sequences reported in this study were deposited in GenBank under the following accession numbers: FM897343 to FM897356 for partial archaeal 16S rRNA gene sequences and FM886822 to FM886831 for crenarchaeotic amoA gene sequences.

\section{Results}

3.1. Environmental Variables. Buhovo and Sliven samples differed in their geochemistry and the levels of $U$ and HM contamination. BuhC and BuhD were sampled (Chromic cambisols) from different soil depths, while Sliv was a sandy gravel material collected from a mine waste pile. The texture of BuhC (20 cm at soil depth) was classified as sandy clay (35\% silt and $54 \%$ clay), whereas BuhD (40 cm at soil depth) was classified as clay (38\% silt and $60 \%$ clay). The bulk density of Buh soil varied in depth from $1.5-1.6 \mathrm{~g} \mathrm{~cm}^{-3}(20 \mathrm{~cm})$ to $1.7-1.8 \mathrm{~g} \mathrm{~cm}^{-3}(40 \mathrm{~cm})$. Soil porosity was $36-40 \%(20 \mathrm{~cm})$ and $25-30 \%(40 \mathrm{~cm})$ (personal communication). There is no data concerning the texture and geochemistry of Sliv substratum, except the organic matter content $(0.3 \%)$ and $\mathrm{pH}(7.5)$. The organic matter content of the Buh samples was $2.8 \%$ for BuhC and $1.6 \%$ for BuhD. The total amount of nitrogen decreased from $1.19 \mathrm{~g} \mathrm{~kg}^{-1}(20 \mathrm{~cm})$ to $1.03 \mathrm{~g} \mathrm{~kg}^{-1}(40 \mathrm{~cm})$, while the total amount of phosphorus was not significantly different between the two soil layers $-0.53 \mathrm{~g} \mathrm{~kg}^{-1}(20 \mathrm{~cm})$ and $0.51 \mathrm{~g} \mathrm{~kg}^{-1}(40 \mathrm{~cm})$. The $\mathrm{pH}_{\mathrm{H}_{2} \mathrm{O}}$ of BuhC and BuhD was slightly acidic ( $\mathrm{pH} 6.9$ and 6.6, resp.).

The main pollutants were $\mathrm{Cu}$ and $\mathrm{Zn}$ (BuhC, BuhD, and Sliv), U (BuhC and Sliv), Cr (BuhC and BuhD), As (BuhC 
TABLE 1: Physicochemical characteristics of samples from three sites in Bulgaria polluted by uranium mining activities, expressed as means \pm standard deviation $(n=15)$.

\begin{tabular}{|c|c|c|c|c|c|}
\hline Parameter & $D$ & $\mathrm{BC}$ & BuhC & BuhD & Sliv \\
\hline $\mathrm{pH}$ & - & - & $6.9 \pm 0.3$ & $6.6 \pm 0.2$ & $7.5 \pm 0.3$ \\
\hline $\mathrm{OM}$ & $\%$ & - & $2.8 \pm 1.3$ & $1.6 \pm 1.0$ & $0.3 \pm 0.1$ \\
\hline $\mathrm{NO}_{3}-\mathrm{N}$ & $\mathrm{mg} / \mathrm{kg}$ & - & $21.6 \pm 12.9$ & $9.4 \pm 6.6$ & $19.9 \pm 11.0$ \\
\hline $\mathrm{SO}_{4}$ & $\mathrm{mg} / \mathrm{kg}$ & - & $786 \pm 95.0$ & $1300 \pm 142.0$ & $151 \pm 14.0$ \\
\hline As & $\mathrm{mg} / \mathrm{kg}$ & 3.84 & $274 \pm 13.0^{1}$ & $72.4 \pm 2.8^{1}$ & $412 \pm 22.0^{1}$ \\
\hline $\mathrm{Cd}$ & $\mathrm{mg} / \mathrm{kg}$ & 0.15 & $2.4 \pm 1.3^{1}$ & $1.1 \pm 1.2$ & $2.7 \pm 1.8^{1}$ \\
\hline Co & $\mathrm{mg} / \mathrm{kg}$ & ND & $29.5 \pm 1.2$ & $27.2 \pm 1.2$ & $22.4 \pm 1.4$ \\
\hline $\mathrm{Cr}$ & $\mathrm{mg} / \mathrm{kg}$ & 51.00 & $89.6 \pm 2.6$ & $95.2 \pm 7.4$ & $8.6 \pm 1.9$ \\
\hline $\mathrm{Cu}$ & $\mathrm{mg} / \mathrm{kg}$ & 47.34 & $236 \pm 11.4^{1}$ & $101 \pm 21.0$ & $3410 \pm 87.0^{1}$ \\
\hline $\mathrm{Ni}$ & $\mathrm{mg} / \mathrm{kg}$ & 36.41 & $75.2 \pm 13.4$ & $98.4 \pm 8.9^{1}$ & $37.0 \pm 11.0$ \\
\hline $\mathrm{Pb}$ & $\mathrm{mg} / \mathrm{kg}$ & 19.19 & $674 \pm 39.4^{1}$ & $126 \pm 16.3$ & $5160 \pm 49.9^{1}$ \\
\hline $\mathrm{Zn}$ & $\mathrm{mg} / \mathrm{kg}$ & 54.98 & $448 \pm 52.0^{1}$ & $464 \pm 23.1^{1}$ & $1270 \pm 98.4^{1}$ \\
\hline $\mathrm{U}$ & $\mathrm{mg} / \mathrm{kg}$ & $0.3-11^{*}$ & $200 \pm 21.2$ & $78.4 \pm 8.7$ & $374 \pm 11.2$ \\
\hline $\mathrm{TI}_{\mathrm{As}}$ & - & - & $1.63 \pm 0.08$ & $0.43 \pm 0.02$ & $2.45 \pm 0.13$ \\
\hline $\mathrm{TI}_{\mathrm{Cd}}$ & - & - & $0.03 \pm 0.01$ & $0.01 \pm 0.00$ & $0.03 \pm 0.02$ \\
\hline $\mathrm{TI}_{\mathrm{Co}}$ & - & - & $0.05 \pm 0.00$ & $0.05 \pm 0.00$ & $0.04 \pm 0.00$ \\
\hline $\mathrm{TI}_{\mathrm{Cr}}$ & - & - & $1.26 \pm 0.03$ & $1.34 \pm 0.1$ & $0.12 \pm 0.02$ \\
\hline $\mathrm{TI}_{\mathrm{Cu}}$ & - & - & $6.74 \pm 0.32$ & $2.88 \pm 0.60$ & $97.43 \pm 2.50$ \\
\hline $\mathrm{TI}_{\mathrm{Ni}}$ & - & - & $0.75 \pm 0.13$ & $0.98 \pm 0.09$ & $0.37 \pm 0.11$ \\
\hline $\mathrm{TI}_{\mathrm{Pb}}$ & - & - & $1.03 \pm 0.06$ & $0.19 \pm 0.02$ & $7.90 \pm 0.08$ \\
\hline $\mathrm{TI}_{\mathrm{Zn}}$ & - & - & $3.89 \pm 0.45$ & $4.03 \pm 0.00$ & $11.04 \pm 0.86$ \\
\hline $\mathrm{TI}_{\text {sum }}$ & - & - & 15.38 & 9.91 & 119.38 \\
\hline
\end{tabular}

${ }^{1}$ Value above the maximum allowable concentration referring to Bulgarian legislation [47]. ${ }^{*}$ Values according to UNSCEAR [48]. ND: no data; $n$ : number of samples; D: dimension; BC: background concentrations referring to Bulgarian legislation [47]; $\mathrm{TI}_{\text {sum }}$ : sum of toxicity indices of heavy metals (except $\mathrm{U}$ ) and metalloid As.

and Sliv), $\mathrm{Pb}$ (Sliv), and sulfates (BuhD) (Table 1). All sites were highly contaminated as shown by their individual $\mathrm{TI}_{i}$ (i-heavy metal with $\mathrm{TI}>1.0$ ) and $\mathrm{TI}_{\text {sum }}$, which decreased as follows: Sliv (119.38) > BuhC (15.38) > BuhD (9.91). Moreover, the level of toxicity might actually be stronger if the values took into account $\mathrm{Mn}$ (BuhC and BuhD) and $\mathrm{U}$ (BuhC and Sliv), since their concentrations were also high. However, the $\mathrm{TI}_{\text {sum }}$ did not include these due to a lack of ED50 data.

3.2. Phylogenetic Diversity of Archaeal and amoA Gene Sequences. A total of 355 archaeal clones (156 from BuhC, 128 from BuhD, and 71 from Sliv) and $229 \mathrm{amoA}$ gene clones (107 from BuhC, 99 from BuhD, and 23 from Sliv) were selected, and their $16 \mathrm{~S}$ rDNA inserts were analysed by RFLP. The clones sequenced were grouped into 19 (archaeal) and 15 (amoA) OTUs, and out of these 14 OTUs and 10 OTUs were unique, respectively. The rarefaction curves of the archaeal BuhC ( $3.99 \pm 0.24$ OTUs), BuhD ( $6.99 \pm 0.07$ OTUs), and Sliv (1.99 \pm 0.06 OTUs) clone libraries were saturated, indicating that they completely covered the natural archaeal diversity of the samples and that the observed OTUs were a good representation of the archaeal community richness (Figure 2). The estimates of archaeal richness (Chao 1, ACE) and diversity (Shannon-Weiner index) predicted the highest values of indices in BuhD, followed by the BuhC and Sliv clone libraries (Table 2).

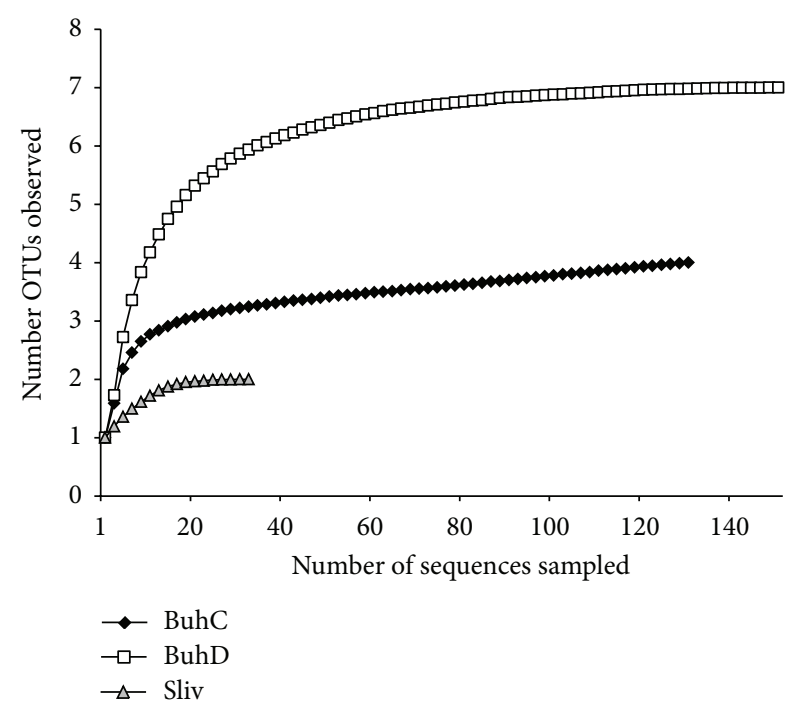

FIGURE 2: Rarefaction curves indicating archaeal $16 \mathrm{~S}$ rRNA richness within BuhC (SSL 97\%), BuhD (SSL 94\%), and Sliv (SSL 91\%) clone libraries.

3.3. Archaeal Community Composition. The $16 \mathrm{~S}$ rRNA gene sequences identified in BuhC, BuhD, and Sliv belonged to the 1.1b/Nitrososphaera cluster of Crenarchaeota (Figure 3). Representatives of other crenarchaeotic clades or other archaeal phyla were not detected in this study. 
TABle 2: Predicted richness (Chao 1 and ACE) and diversity (Shannon-Weiner index) of BuhC, BuhD, and Sliv 16S rDNA archaeal clone libraries, expressed as means \pm standard deviation.

\begin{tabular}{lcccccc}
\hline Clone library & Number of clones & Number of OTUs & Number of singletons/doubletons & Chao 1 & ACE & Shannon-Weiner index \\
\hline BuhC $^{\mathrm{a}}$ & 156 & 7 & 4 & $4 \pm 0.25$ & N/A & $0.97 \pm 0.10$ \\
BuhD $^{\mathrm{b}}$ & 128 & 8 & 1 & $7 \pm 0.00$ & $7 \pm 0.00$ & $1.51 \pm 0.13$ \\
Sliv $^{\mathrm{c}}$ & 71 & 3 & 1 & $2 \pm 0.00$ & $2 \pm 0.00$ & $0.32 \pm 0.24$ \\
\hline
\end{tabular}

OTUs were defined at ${ }^{\mathrm{a}} 3 \%,{ }^{\mathrm{b}} 6 \%$, and ${ }^{\mathrm{c}} 9 \%$ differences in $16 \mathrm{~S}$ rRNA gene sequences.

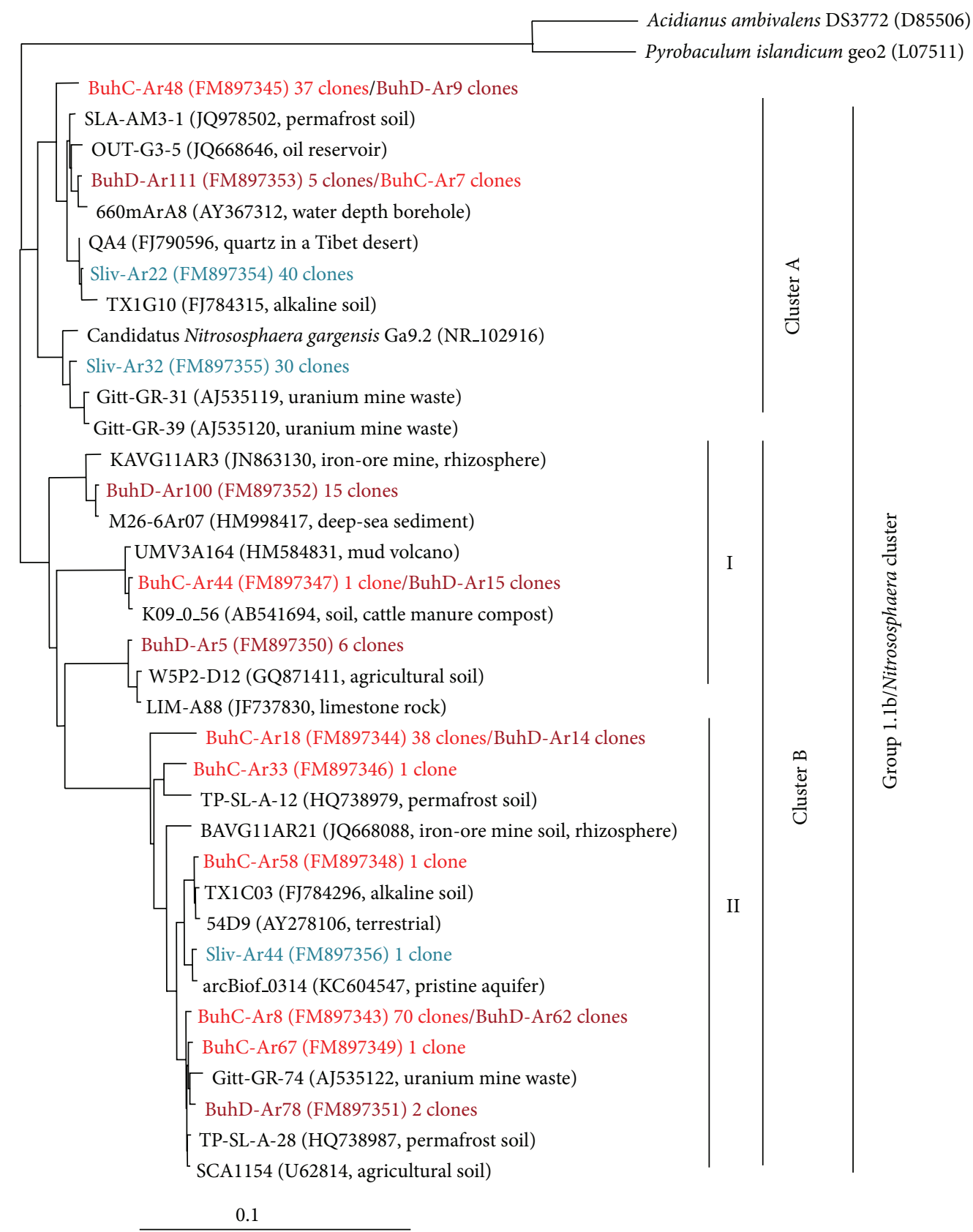

Figure 3: Phylogenetic analysis of archaeal 16S rRNA gene sequences retrieved from uranium mining sites BuhC, BuhD, and Sliv. The tree was constructed using the neighbour-joining method. The $16 \mathrm{~S}$ rRNA sequences of Acidianus ambivalens DS3772 and Pyrobaculum islandicum geo 2 were used as an outgroup. The scale bar represents 0.1 changes per nucleotide position. 


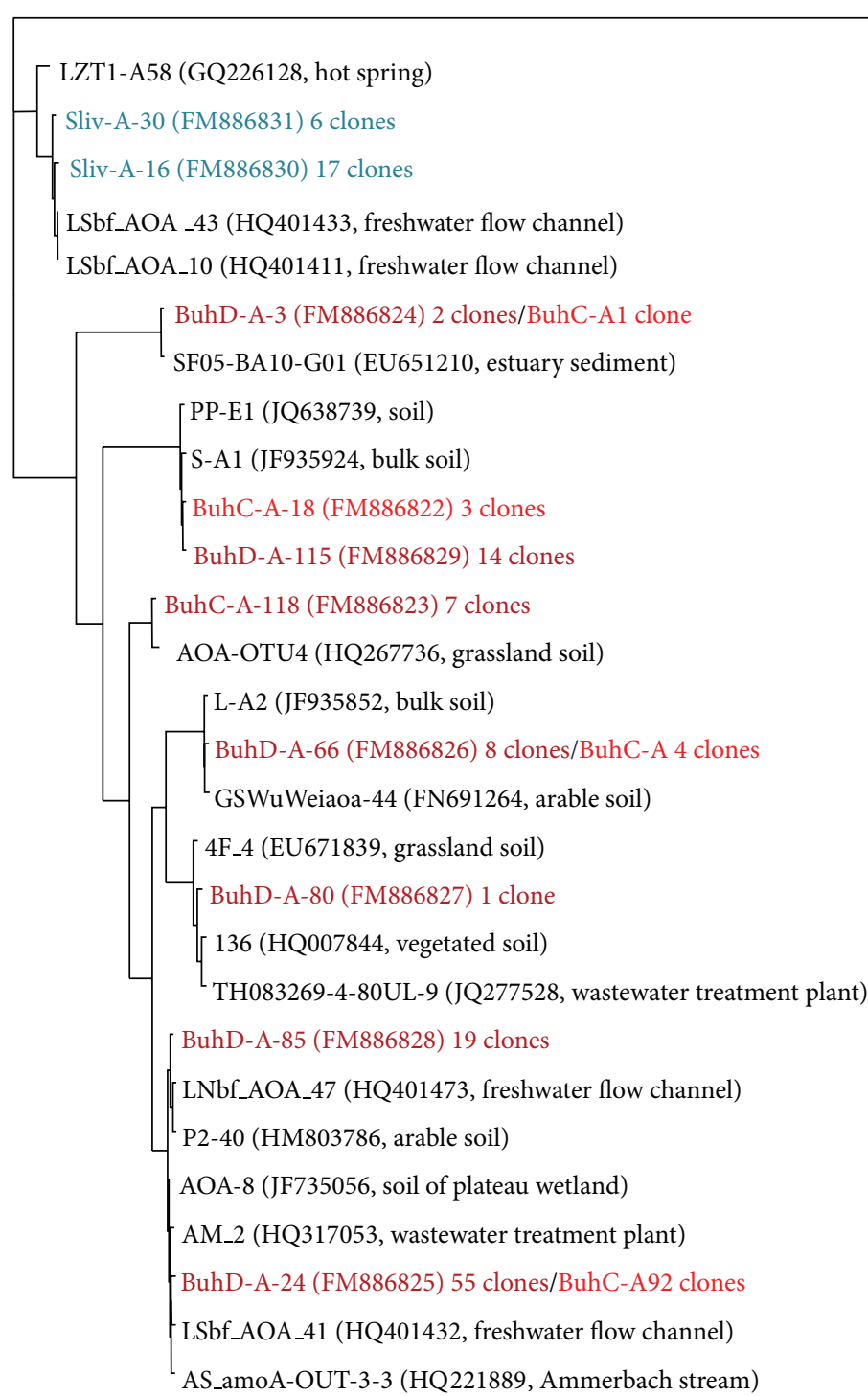

Nitrospira briensis (U76553)

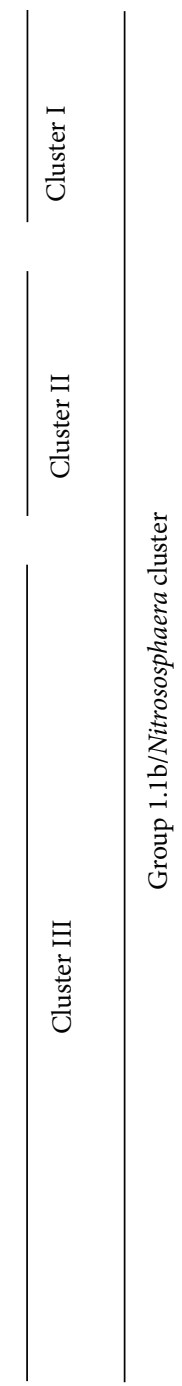

0.1

Figure 4: Phylogenetic analysis of archaeal amoA gene sequences retrieved from uranium mining sites BuhC, BuhD, and Sliv. The tree was constructed using the neighbour-joining method. The amoA sequence of Nitrospira briensis was used as an outgroup. The scale bar represents 0.1 changes per nucleotide position.

The crenarchaeotic sequences were grouped into clusters (A and B; Figure 3). Cluster A involved 16S rRNA gene sequences retrieved mainly from the highly polluted environments of Sliv and BuhC. Cluster B consisted of OTUs from the BuhC and BuhD (226 of 227 clones) libraries. The latter cluster was separated into subcluster IB, generated by the sequences of the BuhD clone library (36 of 37 clones), and subcluster IIB, which mainly consisted of clones belonging to the BuhC and BuhD libraries (190 of 196 clones).

There were common (BuhC-Ar8, BuhC-Ar18, BuhCAr48, and BuhD-Ar111) 16S rRNA gene archaeal sequences in the clone libraries of BuhC and BuhD. We did not retrieve any gene sequences common to the Sliv and Buh substrata.

All retrieved 16S rRNA gene sequences matched to sequences of uncultured archaea, except Sliv-Ar32, which was affiliated with the cultured archaeon Candidatus Nitrososphaera gargensis (NR_102916).

3.4. Composition of the amoA Community. Phylogenetic analysis of 10 archaeal amoA OTUs revealed a high sequence identity (98-100\%) with ammonia-oxidizing crenarchaeotes. Cluster I from the phylogenetic tree of the amoA gene sequences was formed by two OTUs from Sliv, whereas clusters II and III were only composed of OTUs from the Buhovo soil environments (Figure 4). In total, all amoA OTUs were presented in a relatively small number of clones (1-15 clones), except BuhD-A-24 and its analogue OTU from BuhC, which consisted of 55 and 92 clones, respectively.

All retrieved archaeal amoA sequences were matched with uncultured crenarchaeotes. 
Protein sequences derived from the same samples were also analysed, and the data validated our DNA results (data not published). The protein sequences exhibited 96$100 \%$ similarity to the closest matched GenBank sequences retrieved from terrestrial, estuarine, and hot spring environments.

\section{Discussion}

The BuhC, BuhD, and Sliv archaeal communities appear to be composed solely of members of the soil-freshwatersubsurface group (1.1b) of Crenarchaeota, which was recently assigned by Bartossek et al. [49] as Nitrososphaera cluster. The presence of Crenarchaeota in these sites was not surprising, since these organisms are widespread $[4,7,50]$, even in environments highly polluted with $U$ and HMs $[5,7,13,51]$. Probably, the selection and propagation of only $1.1 \mathrm{~b}$ Crenarchaeota in Buhovo and Sliven are passed under the power of $\mathrm{U}$ and HM pollution. Supporting this notion, Geissler et al. [52], Reitz et al. [14], and Radeva et al. [53] reported a strong reduction in archaeal diversity and a shift from Crenarchaeota $1.1 \mathrm{a}$ to $1.1 \mathrm{~b}$ in soil samples supplemented with uranyl nitrate. The adverse effects of $U$ were also confirmed by Porat et al. [5], who found low archaeal diversity in U-/nitratecontaminated sediments of the Oak Ridge stream (TN, USA).

The importance of the substratum and the level of pollution in the pattern of crenarchaeotic distribution is evident from the archaeal phylogenetic tree (Figure 3), where OTUs are grouped in one large cluster (B) based on 16S rRNA gene sequences from Buhovo soil (9 of 10 OTUs/226 of 227 clones) and another smaller cluster (A) formed of OTUs from the most polluted environments, Sliv and BuhC (4 of 6 OTUs/ 114 of 128 clones). There are no common 16S rRNA gene sequences from the two substrata (Buh soil and Sliv sandy gravel matter) studied.

The distinct physical and geochemical niches of the sites harbour characteristic crenarchaeotic populations (Figure 3): (i) typical soil species tolerant towards environmental extremes, including resistance to $U$ and HMs (members of subcluster IIB); (ii) depth specific species, probably, sensitive to $U$ and HMs (members of subcluster IB); and (iii) resistant to $\mathrm{U}$ and HM soil and rocky inhabitants (cluster A). All OTUs correspond to terrestrial environmental matches, except SlivAr44, BuhD-Ar100, and BuhD-Ar111, which exhibit high similarity (99-100\%) with gene sequences derived from aquatic environments: groundwater (KC604547), deep-sea sediments (HM998417), and seawater at depths of $660 \mathrm{~m}$ (AY367312), respectively. In general, the above-mentioned water-related OTUs are only represented by a small number of clones (1-15).

The Buh soil environments comprise more complex and more diverse archaeal communities: $84 \%$ of OTUs and $80 \%$ of archaeal clones are from Buh, which validates data from Ochsenreiter et al. [7] indicating that the $1.1 \mathrm{~b}$ crenarchaeotic clade is a typical "soil lineage."

Archaeal diversity in Buh soil is relatively low, varying from 0.97 (BuhC) to 1.51 (BuhD), and is depth dependent. Archaeal communities of the two soil depths include both common (BuhC-Ar8, BuhC-Ar18, BuhC-Ar44, BuhCAr48, and BuhD-Ar111) and depth-specific 16S rRNA gene sequences, the latter of which are represented by a small number of clones (1-15 clones). The dominant OTU BuhCAr8 is equally distributed in soil depth, comprising $45 \%$ and $48 \%$ of clones retrieved from BuhC and BuhD, respectively. Moreover, it is closely affiliated (99\% SSL) with the uncultured crenarchaeote Gitt-GR-74 (AJ535122), which is found in uranium mill tailing in Saxony, Germany [13].

A trend for depth dependency in archaeal distribution was also observed in other studies, which indicate that Crenarchaeota are more abundant in deeper soil layers [5457] and that archaeal : bacterial ratios increase with soil depth [2]. In the aforementioned studies, increasing abundance of crenarchaeotes correlated with decreasing nutrient (organic carbon and inorganic nitrogen) and oxygen concentrations in deeper soil layers. In agreement with the above-mentioned statements, we can speculate for BuhD that the diversity of Crenarchaeota is favoured by the nutritional and oxygen status of this soil depth and its low levels of $U$ and HM pollution. The relative opposite conditions in BuhC soil layer comparing to BuhD (higher organic matter content, higher aeration in the upper soil layer, and higher levels of $U$ and HMs) limit its archaeal diversity mainly to three dominant OTUs (BuhC-Ar8, BuhC-Ar18, and BuhC-Ar48) that harboured $93 \%$ of clones in the BuhC clone library.

The sandy gravel substratum of Sliv and its high level of pollution make this environment very unfavourable for archaeal proliferation. The inhabitants of Sliv are presented by two main OTUs (Sliv-Ar32 and Sliv-Ar22) that comprise $99 \%$ of clones. All archaeal 16S rRNA gene sequences retrieved from Sliv correspond with uncultured crenarchaeotic matches, except Sliv-Ar32, which exhibits a $99 \%$ similarity with Candidatus Nitrososphaera gargensis Ga9.2. According to Spang et al. [58], Ca. N. gargensis is well adapted to HM-contaminated environments and encodes a number of HM resistance genes that convey the genetic capacity to respond to environmental changes. The close similarity of Sliv-Ar32 to Gitt-GR sequences (99\% SSL) recovered from $\mathrm{U}$ mill tailings in Germany also confirms the high tolerance of Sliv-Ar32 towards $U$ and HM pollution. The other, more abundant OTU is Sliv-Ar22 (40 clones), and its dominance in Sliv clone library can be explained by both tolerance towards high levels of pollution and ability of Sliv-Ar22 archaeon to colonize rocky substrata. This sequence exhibits high similarity to the uncultured crenarchaeote QA4 (99\% SSL), which was recovered from quartz rocks located in the highaltitude tundra of Central Tibet [59].

The phylogenetic analysis of archaeal amoA gene sequences retrieved from BuhC, BuhD, and Sliv reveals that the Crenarchaeota inhabiting these locations harbour ammonia oxidizers (Figure 4). The pattern of amoA gene sequence distribution is similar to that of Crenarchaeota with the smallest number of OTUs in the most unfavourable environment of Sliv (2 OTUs/23 clones), followed by the highly polluted BuhC (5 OTUs/107 clones) and the relatively low polluted BuhD (6 OTUs/99 clones). The high number of amoA OTUs in BuhD is related to the highest archaeal diversity in this depth and is due to the favourable conditions 
(low organic matter, nitrogen and oxygen content, and high clayey soil texture) which stimulate not only the archaeal diversity but also the diversity of ammonia-oxidizing archaea. To date, studies [33,60-63] that have investigated the environmental factors that shape amoA gene diversity in oceans, sediments, and soils have identified these factors as key environmental parameters for the proliferation of ammonia-oxidizing archaea.

Forty-six percent of the archaeal amoA OTUs, which comprise $73 \%$ of clones retrieved in this study, affiliate with archaeal amoA gene sequences obtained from freshwater ecosystems [64, 65] and wastewater treatment plants [66]. These belong to the "soil and other environments" cluster, as proposed by Prosser and Nicol [67]. The other amoA OTUs (all from BuhD and BuhC) exhibit gene sequences closely related to those retrieved from soil environments like bulk [60] and arable (FN691264, HM803786) soils, grassland (HQ267736, EU671839), and semiarid soil (JQ638739) that belong also to the "soil and other environments" cluster [67].

BuhC and BuhD are very different environments with regard to soil texture, nutrients, oxygen (low soil porosity), and pollution status. Nevertheless, the two environments are inhabited by ammonia-oxidizing archaea as determined by the presence of the amoA gene sequence; BuhD-A-24 comprised $23 \%(\mathrm{BuhD})$ and $41 \%$ (BuhC) of all retrieved amoA clones. It is likely that the exclusive domination of BuhDA-24 in Buhovo soil depths is a result of the adverse effects of pollution that reduce archaeal amoA diversity and the selection of only a few resistant gene sequences. We did not detect novel archaeal amoA clusters that would indicate the existence of special U- and HM-resistant ammonia-oxidizing archaea in the sites studied. This reveals the widespread distribution of ammonia-oxidizing archaea and the capacity of some species to tolerate high levels of $\mathrm{U}$ and HMs.

\section{Conclusions}

Phylogenetic analysis revealed that all archaeal $16 \mathrm{~S}$ rRNA gene sequences assessed in this study belong to the 1.1b/ Nitrososphaera cluster of Crenarchaeota. The diversity of crenarchaeotic communities that inhabit the three sites of interest was very low, especially in the high U- and HM-polluted, sandy-stone environment of the Sliv mine. The archaeal communities of Buh and Sliv mines were distinct to each site and did not harbour common gene sequences. We did not detect novel crenarchaeotic and amoA gene clusters, indicating that the polluted environments of Buh and Sliv are inhabited by typical archaeal soil lineages. It is likely that these archaeal soil lineages were selected by the multifactorial nature of the local environment, resulting in the development of tolerance of indigenous archaea to high $\mathrm{U}$ and HM pollution. The archaeal amoA gene sequences detected in BuhC, BuhD, and Sliv supposed that ammonia-oxidizing archaea participate in nitrogen cycling in environments highly polluted with $U$ and HMs. This study will be helpful in understanding the archaeal and ammonia-oxidizing archaeal diversities in soils polluted with $\mathrm{U}$ and HMs.

\section{Conflict of Interests}

The authors declare that there is no conflict of interests regarding the publication of this paper.

\section{Acknowledgment}

This study was financially supported by the Institute of Resource Ecology, Helmholtz-Centre Dresden-Rossendorf, Germany.

\section{References}

[1] D. R. Rogers and K. L. Casciotti, "Abundance and diversity of archaeal ammonia oxidizers in a coastal groundwater system," Applied and Environmental Microbiology, vol. 76, no. 24, pp. 7938-7948, 2010.

[2] D. Kemnitz, S. Kolb, and R. Conrad, "High abundance of Crenarchaeota in a temperate acidic forest soil," FEMS Microbiology Ecology, vol. 60, no. 3, pp. 442-448, 2007.

[3] E. Teira, P. Lebaron, H. van Aken, and G. J. Herndl, "Distribution and activity of Bacteria and Archaea in the deep water masses of the North Atlantic," Limnology and Oceanography, vol. 51, no. 5, pp. 2131-2144, 2006.

[4] C. Schleper, G. Jurgens, and M. Jonuscheit, "Genomic studies of uncultivated Archaea," Nature Reviews Microbiology, vol. 3, no. 6, pp. 479-488, 2005.

[5] I. Porat, T. A. Vishnivetskaya, J. J. Mosher et al., "Characterization of archaeal community in contaminated and uncontaminated surface stream sediments," Microbial Ecology, vol. 60, no. 4, pp. 784-795, 2010.

[6] K. Zhalnina, P. Dörr de Quadros, F. A. O. Camargo, and E. W. Triplett, "Drivers of archaeal ammonia-oxidizing communities in soil," Frontiers in Microbiology, vol. 3, article 210, 2012.

[7] T. Ochsenreiter, D. Selezi, A. Quaiser, L. Bonch-Osmolovskaya, and C. Schleper, "Diversity and abundance of Crenarchaeota in terrestrial habitats studied by $16 \mathrm{~S}$ RNA surveys and real time PCR," Environmental Microbiology, vol. 5, no. 9, pp. 787-797, 2003.

[8] A. Geissler, Prokaryotic microorganisms in uranium mining waste piles and their interactions with uranium and other heavy metals [Ph.D. thesis], TU Bergakademie Freiberg, Freiberg, Germany, 2007.

[9] T. Reitz, M. L. Merroun, A. Rossberg, and S. Selenska-Pobell, "Interactions of Sulfolobus acidocaldarius with uranium," Radiochimica Acta, vol. 98, no. 5, pp. 249-257, 2010.

[10] K. Takai, D. P. Moser, M. DeFlaun, T. C. Onstott, and J. K. Fredrickson, "Archaeal diversity in waters from deep South African gold mines," Applied and Environmental Microbiology, vol. 67, no. 12, pp. 5750-5760, 2001.

[11] L. Y. Stein, G. Jones, B. Alexander, K. Elmund, C. Wright-Jones, and K. H. Nealson, "Intriguing microbial diversity associated with metal-rich particles from a freshwater reservoir," FEMS Microbiology Ecology, vol. 42, no. 3, pp. 431-440, 2002.

[12] Y. Suzuki, S. D. Kelly, K. M. Kemner, and J. F. Banfield, "Direct microbial reduction and subsequent preservation of uranium in natural near-surface sediment," Applied and Environmental Microbiology, vol. 71, no. 4, pp. 1790-1797, 2005.

[13] G. Radeva and S. Selenska-Pobell, "Archaeal diversity in soils of the uranium mining wastes," Annual Report of Institute of Radiochemistry FZR-373, 2002. 
[14] T. Reitz, A. Geissler, and S. Selenska-Pobell, "Changes in archaeal community of the waste pile Haberland induced by uranyl nitrate treatments," Annual Report of the Institute of Radiochemistry FZR-459, 2006.

[15] K. Kashefi, E. S. Shelobolina, W. C. Elliott, and D. R. Lovley, "Growth of thermophilic and hyperthermophilic Fe(III)reducing microorganisms on a ferruginous smectite as the sole electron acceptor," Applied and Environmental Microbiology, vol. 74, no. 1, pp. 251-258, 2008.

[16] A. J. Francis, J. B. Gillow, C. J. Dodge, R. Harris, T. J. Beveridge, and H. W. Papenguth, "Uranium association with halophilic and non-halophilic Bacteria and Archaea," Radiochimica Acta, vol. 92, no. 8, pp. 481-488, 2004.

[17] T. Reitz, M. L. Merroun, A. Rossberg, R. Steudtner, and S. Selenska-Pobell, "Bioaccumulation of U(VI) by Sulfolobus acidocaldarius under moderate acidic conditions," Radiochimica Acta, vol. 99, no. 9, pp. 543-553, 2011.

[18] M. Pester, C. Schleper, and M. Wagner, “The Thaumarchaeota: an emerging view of their phylogeny and ecophysiology," Current Opinion in Microbiology, vol. 14, no. 3, pp. 300-306, 2011.

[19] M. Könneke, A. E. Bernhard, J. R. de la Torre, C. B. Walker, J. B. Waterbury, and D. A. Stahl, "Isolation of an autotrophic ammonia-oxidizing marine archaeon," Nature, vol. 437, no. 7058, pp. 543-546, 2005.

[20] A. H. Treusch, S. Leininger, A. Kietzin, S. C. Schuster, H.-P. Klenk, and C. Schleper, "Novel genes for nitrite reductase and Amo-related proteins indicate a role of uncultivated mesophilic Crenarchaeota in nitrogen cycling," Environmental Microbiology, vol. 7, no. 12, pp. 1985-1995, 2005.

[21] S. Leininger, T. Urich, M. Schloter et al., "Archaea predominate among ammonia-oxidizing prokaryotes in soils," Nature, vol. 442, no. 7104, pp. 806-809, 2006.

[22] M. J. L. Coolen, B. Abbas, J. van Bleijswijk et al., "Putative ammonia-oxidizing Crenarchaeota in suboxic waters of the Black Sea: a basin-wide ecological study using $16 \mathrm{~S}$ ribosomal and functional genes and membrane lipids," Environmental Microbiology, vol. 9, no. 4, pp. 1001-1016, 2007.

[23] P. Lam, M. M. Jensen, G. Lavik et al., "Linking crenarchaeal and bacterial nitrification to anammox in the Black Sea," Proceedings of the National Academy of Sciences of the United States of America, vol. 104, no. 17, pp. 7104-7109, 2007.

[24] C. Wuchter, B. Abbas, M. J. L. Coolen et al., "Archaeal nitrification in the ocean," Proceedings of the National Academy of Sciences of the United States of America, vol. 103, no. 33, pp. 12317-12322, 2006.

[25] M. Herrmann, A. M. Saunders, and A. Schramm, "Archaea dominate the ammonia-oxidizing community in the rhizosphere of the freshwater macrophyte Littorella uniflora," Applied and Environmental Microbiology, vol. 74, no. 10, pp. 3279-3283, 2008.

[26] J. R. de la Torre, C. B. Walker, A. E. Ingalls, M. Könneke, and D. A. Stahl, "Cultivation of a thermophilic ammonia oxidizing archaeon synthesizing crenarchaeol," Environmental Microbiology, vol. 10, no. 3, pp. 810-818, 2008.

[27] R. Hatzenpichler, E. V. Lebedeva, E. Spieck et al., "A moderately thermophilic ammonia-oxidizing crenarchaeote from a hot spring," Proceedings of the National Academy of Sciences of the United States of America, vol. 105, no. 6, pp. 2134-2139, 2008.

[28] L. J. Reigstad, A. Richter, H. Daims, T. Urich, L. Schwark, and C. Schleper, "Nitrification in terrestrial hot springs of Iceland and Kamchatka," FEMS Microbiology Ecology, vol. 64, no. 2, pp. 167-174, 2008.
[29] J. Pouliot, P. E. Galand, C. Lovejoy, and W. F. Vincent, "Vertical structure of archaeal communities and the distribution of ammonia monooxygenase A gene variants in two meromictic High Arctic lakes," Environmental Microbiology, vol. 11, no. 3, pp. 687-699, 2009.

[30] P. W. J. J. van der Wielen, S. Voost, and D. van der Kooij, "Ammonia-oxidizing Bacteria and Archaea in groundwater treatment and drinking water distribution systems," Applied and Environmental Microbiology, vol. 75, no. 14, pp. 4687-4695, 2009.

[31] H.-D. Park, G. F. Wells, H. Bae, C. S. Griddle, and C. A. Francis, "Occurrence of ammonia-oxidizing Archaea in wastewater treatment plant bioreactors," Applied and Environmental Microbiology, vol. 72, no. 8, pp. 5643-5647, 2006.

[32] G. W. Nicol, S. Leininger, C. Schleper, and J. I. Prosser, "The influence of soil $\mathrm{pH}$ on the diversity, abundance and transcriptional activity of ammonia oxidizing Archaea and Bacteria," Environmental Microbiology, vol. 10, no. 11, pp. 2966-2978, 2008.

[33] K. L. Adair and E. Schwartz, "Evidence that ammonia-oxidizing Archaea are more abundant than ammonia-oxidizing Bacteria in semiarid soils of Northern Arizona, USA," Microbial Ecology, vol. 56, no. 3, pp. 420-426, 2008.

[34] L.-M. Zhang, P. R. Offre, J.-Z. He, D. T. Verhamme, G. W. Nicol, and J. I. Prosser, "Autotrophic ammonia oxidation by soil thaumarchaea," Proceedings of the National Academy of Sciences of the United States of America, vol. 107, no. 40, pp. 17240-17245, 2010.

[35] I. S. Kaurichev, "Organic matter determination in soil samples by Thurin's method," in Manual of Pedological Practices, pp. 212241, Kolos, Moscow, Russia, 1980.

[36] R. J. Bertolacini and J. E. Barney II, "Colorimetric determination of sulfate with barium chloranilate," Analytical Chemistry, vol. 29, no. 2, pp. 281-283, 1957.

[37] D. R. Keeney and D. W. Nelson, "Nitrogen-inorganic forms," in Methods of Soil Analysis, Part 2, A. L. Page, R. H. Miller, and D. Keeney, Eds., vol. 9 of Agronomy Monograph, pp. 643-698, ASA and SSSA, Madison, Wis, USA, 2nd edition, 1982.

[38] S. Selenska-Pobell, G. Kampf, K. Flemming, G. Radeva, and G. Satchanska, "Bacterial diversity in soil samples from two uranium waste piles as determined by rep-APD, RISA and 16S rDNA retrieval," Antonie van Leeuwenhoek, vol. 79, no. 2, pp. 149-161, 2001.

[39] E. F. DeLong, "Archaea in coastal marine environments," Proceedings of the National Academy of Sciences of the United States of America, vol. 89, no. 12, pp. 5685-5689, 1992.

[40] C. A. Francis, K. J. Roberts, J. M. Beman, A. E. Santoro, and B. B. Oakley, "Ubiquity and diversity of ammonia-oxidizing Archaea in water columns and sediments of the ocean," Proceedings of the National Academy of Sciences of the United States of America, vol. 102, no. 41, pp. 14683-14688, 2005.

[41] T. Huber, G. Faulkner, and P. Hugenholtz, "Bellerophon: a program to detect chimeric sequences in multiple sequence alignments," Bioinformatics, vol. 20, no. 14, pp. 2317-2319, 2004.

[42] J. D. Thompson, D. G. Higgins, and T. J. Gibson, "CLUSTAL W: improving the sensitivity of progressive multiple sequence alignment through sequence weighting, position-specific gap penalties and weight matrix choice," Nucleic Acids Research, vol. 22, no. 22, pp. 4673-4680, 1994. 
[43] P. D. Schloss, S. L. Westcott, T. Ryabin et al., "Introducing mothur: open-source, platform-independent, community-supported software for describing and comparing microbial communities," Applied and Environmental Microbiology, vol. 75, no. 23, pp. 7537-7541, 2009.

[44] A. Chao, "Nonparametric estimation of the number of classes in a population," Scandinavian Journal of Statistics, vol. 11, pp. 265-270, 1984.

[45] A. E. Magurran, Ecological Diversity and Its Measurements, Princeton University Press, Princeton, NJ, USA, 1988.

[46] G. Welp, "Inhibitory effects of the total and water-soluble concentrations of nine different metals on the dehydrogenase activity of a loess soil," Biology and Fertility of Soils, vol. 30, no. 1-2, pp. 132-139, 1999.

[47] "Bulgarian legislation, Ordinance 3/1. 08," Ministry of Environment and Water, 2008, http://www3.moew.government.bg/? show $=$ top\&cid $=388$.

[48] UNSCEAR-United Nations Scientific Committee on the Effects of Atomic Radiation, Sources and Effects of Ionizing Radiation, 1993.

[49] R. Bartossek, A. Spang, G. Weidler, A. Lanzen, and C. Schleper, "Metagenomic analysis of ammonia-oxidizing Archaea affiliated with the soil group," Frontiers in Microbiology, vol. 3, article 208, 2012.

[50] S. T. Bates, D. Berg-Lyons, J. G. Caporaso, W. A. Walters, R. Knight, and N. Fierer, "Examining the global distribution of dominant archaeal populations in soil," ISME Journal, vol. 5, no. 5, pp. 908-917, 2011.

[51] G. W. Weidler, M. Dornmayr-Pfaffenhuemer, F. W. Gerbl, W. Heinen, and H. Stan-Lotter, "Communities of Archaea and Bacteria in a subsurface radioactive thermal spring in the Austrian central alps, and evidence of ammonia-oxidizing Crenarchaeota," Applied and Environmental Microbiology, vol. 73, no. 1, pp. 259-270, 2007.

[52] A. Geissler, T. Reitz, J. Tschikov, and S. Selenska-Pobell, "Influence of $U,(V I)$ and nitrate on microbial communities of uranium mining waste," Geophysical Research Abstracts, vol. 8, Article ID 04336, 2006.

[53] G. Radeva, V. Buchvarova, K. Flemming, T. Reitz, and S. Selenska-Pobell, "Microbial diversity in highly contaminated uranium mining wastes. Part A: archaeal diversity," Annual Report of Institute of Radiochemistry FZR-511, 2008.

[54] C. M. Hansel, S. Fendorf, P. M. Jardine, and C. A. Francis, "Changes in bacterial and archaeal community structure and functional diversity along a geochemically variable soil profile," Applied and Environmental Microbiology, vol. 74, no. 5, pp. 1620-1633, 2008.

[55] M. Hartmann, S. Lee, S. J. Hallam, and W. W. Mohn, "Bacterial, archaeal and eukaryal community structures throughout soil horizons of harvested and naturally disturbed forest stands," Environmental Microbiology, vol. 11, no. 12, pp. 3045-3062, 2009.

[56] K. G. Eilers, S. Debenport, S. Anderson, and N. Fierer, "Digging deeper to find unique microbial communities: the strong effect of depth on the structure of bacterial and archaeal communities in soil," Soil Biology and Biochemistry, vol. 50, pp. 58-65, 2012.

[57] A. E. Santoro and K. L. Casciotti, "Enrichment and characterization of ammonia-oxidizing Archaea from the open ocean: phylogeny, physiology and stable isotope fractionation," ISME Journal, vol. 5, no. 11, pp. 1796-1808, 2011.

[58] A. Spang, A. Poehlein, P. Offre et al., "The genome of the ammonia-oxidizing Candidatus Nitrososphaera gargensis: insights into metabolic versatility an environmental adaptations," Environmental Microbiology, vol. 14, no. 12, pp. 3122-3145, 2012.

[59] F. K. Y. Wong, D. C. Lacap, M. C. Y. Lau, J. C. Aitchison, D. A. Cowan, and S. B. Pointing, "Hypolithic microbial community of quartz pavement in the high-altitude tundra of central tibet," Microbial Ecology, vol. 60, no. 4, pp. 730-739, 2010.

[60] M. C. Pereira e Silva, F. Poly, N. Guillaumaud, J. D. van Elsas, and J. F. Salles, "Fluctuations in ammonia oxidizing communities across agricultural soils are driven by soil structure and $\mathrm{pH}$," Frontiers in Microbiology, vol. 3, article 77, 2012.

[61] A. C. Mosier and C. A. Francis, "Relative abundance and diversity of ammonia-oxidizing Archaea and Bacteria in the San Francisco Bay estuary," Environmental Microbiology, vol. 10, no. 11, pp. 3002-3016, 2008.

[62] J.-P. Shen, L.-M. Zhang, Y.-G. Zhu, J.-B. Zhang, and J.-Z. He, "Abundance and composition of ammonia-oxidizing Bacteria and ammonia-oxidizing Archaea communities of an alkaline sandy loam," Environmental Microbiology, vol. 10, no. 6, pp. 1601-1611, 2008.

[63] J. Ollivier, W. Natasia, A. Austruy et al., "Abundance and diversity of ammonia oxidizing prokaryotes in the root-rhizosphere complex of Miscanthus x giganteus grown in heavy metalcontaminated soils," Microbial Ecology, vol. 64, no. 4, pp. 10381046, 2012.

[64] M. Herrmann, A. Scheibe, S. Avrahami, and K. Küsel, "Ammonium availability affects the ratio of ammonia-oxidizing Bacteria to ammonia-oxidizing Archaea in simulated creek ecosystems," Applied and Environmental Microbiology, vol. 77, no. 5, pp. 1896-1899, 2011.

[65] H. Jiang, Q. Huang, H. Dong et al., "RNA-based investigation of ammonia-oxidizing Archaea in hot springs of Yunnan Province, China," Applied and Environmental Microbiology, vol. 76, no. 13, pp. 4538-4541, 2010.

[66] M. Mußmann, I. Brito, A. Pitcher et al., "Thaumarchaeotes abundant in refinery nitrifying sludges express amoA but are not obligate autotrophic ammonia oxidizers," Proceedings of the National Academy of Sciences of the United States of America, vol. 108, no. 40, pp. 16771-16776, 2011.

[67] J. I. Prosser and G. W. Nicol, "Relative contributions of Archaea and Bacteria to aerobic ammonia oxidation in the environment," Environmental Microbiology, vol. 10, no. 11, pp. 2931-2941, 2008. 

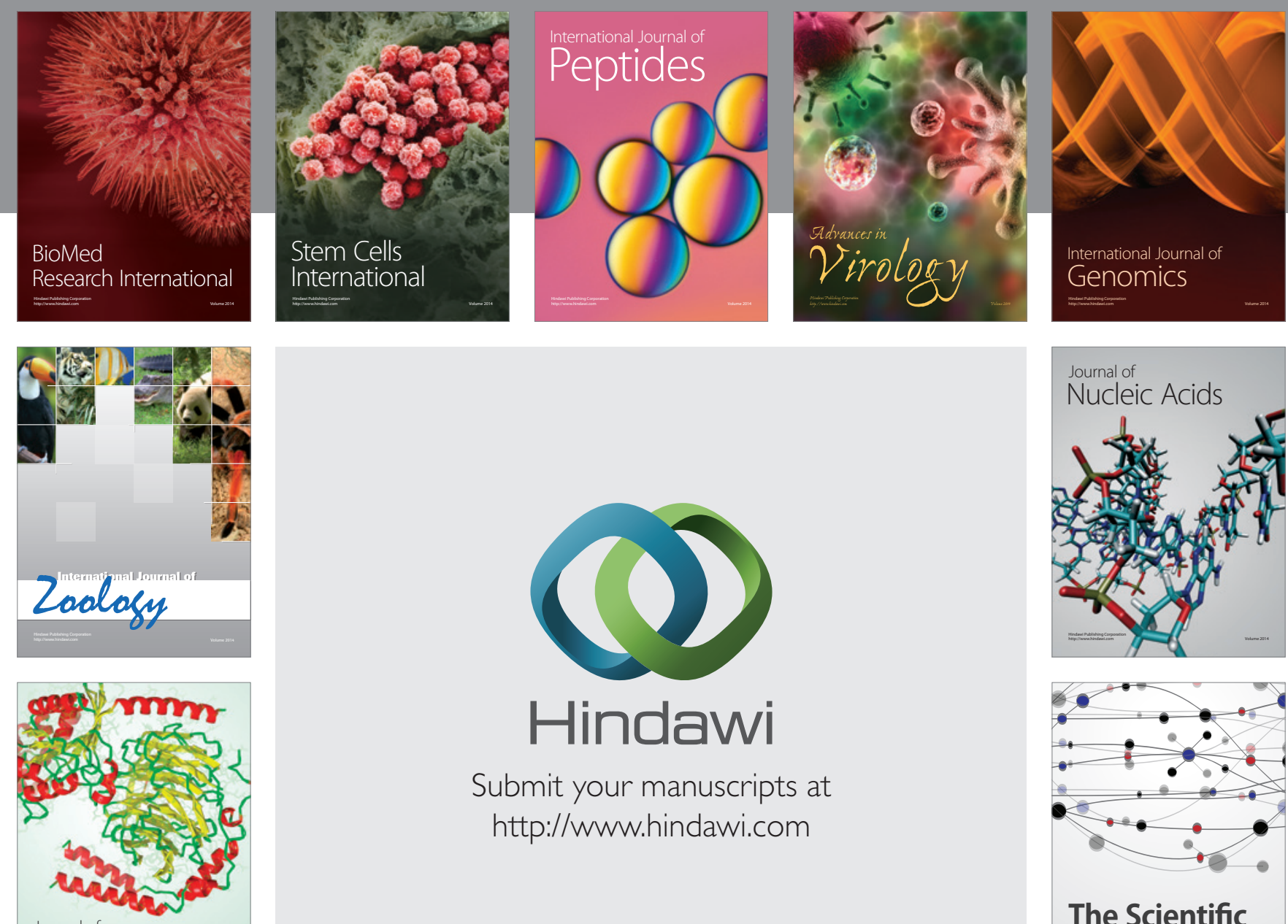

Submit your manuscripts at

http://www.hindawi.com

Journal of
Signal Transduction
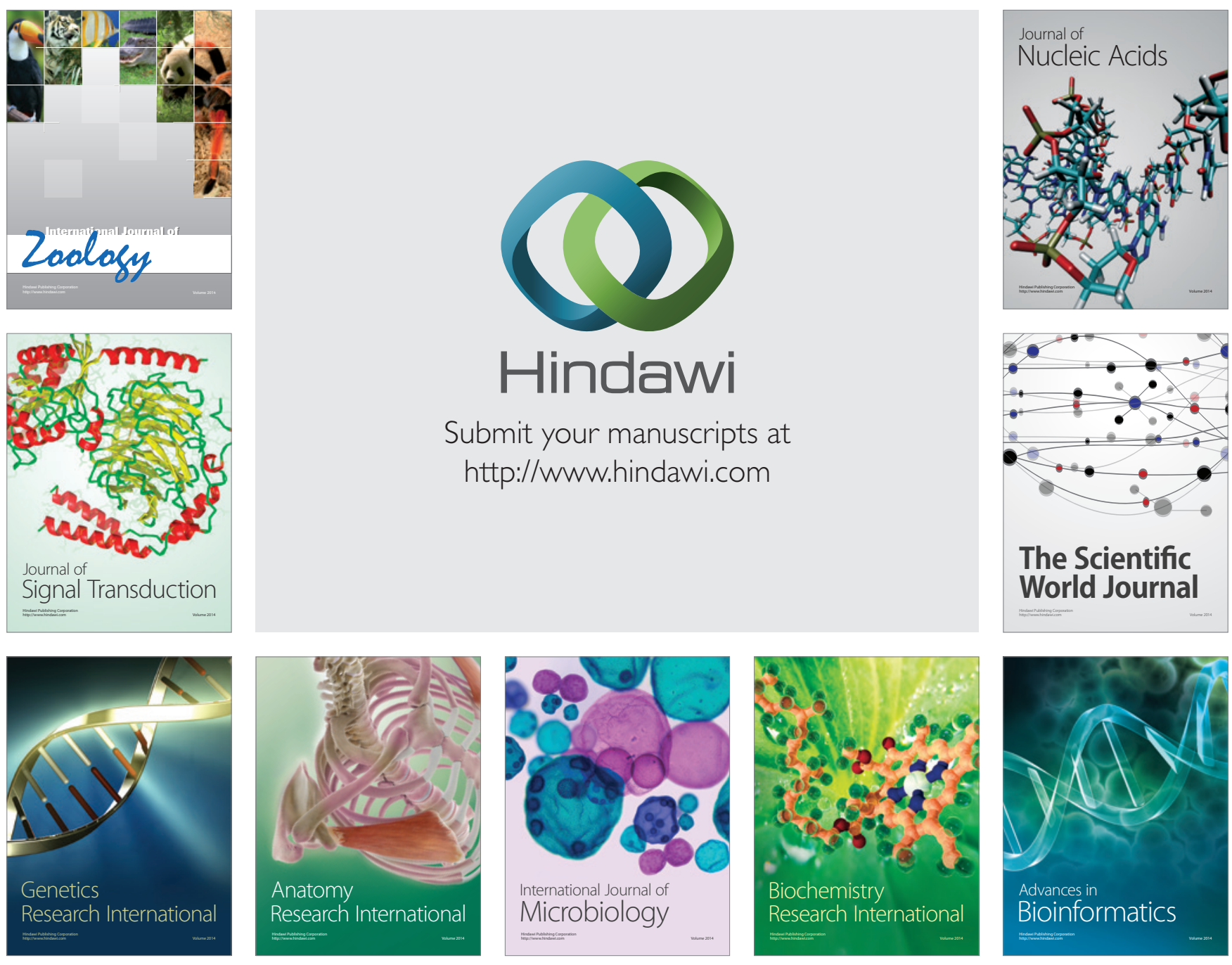

The Scientific World Journal
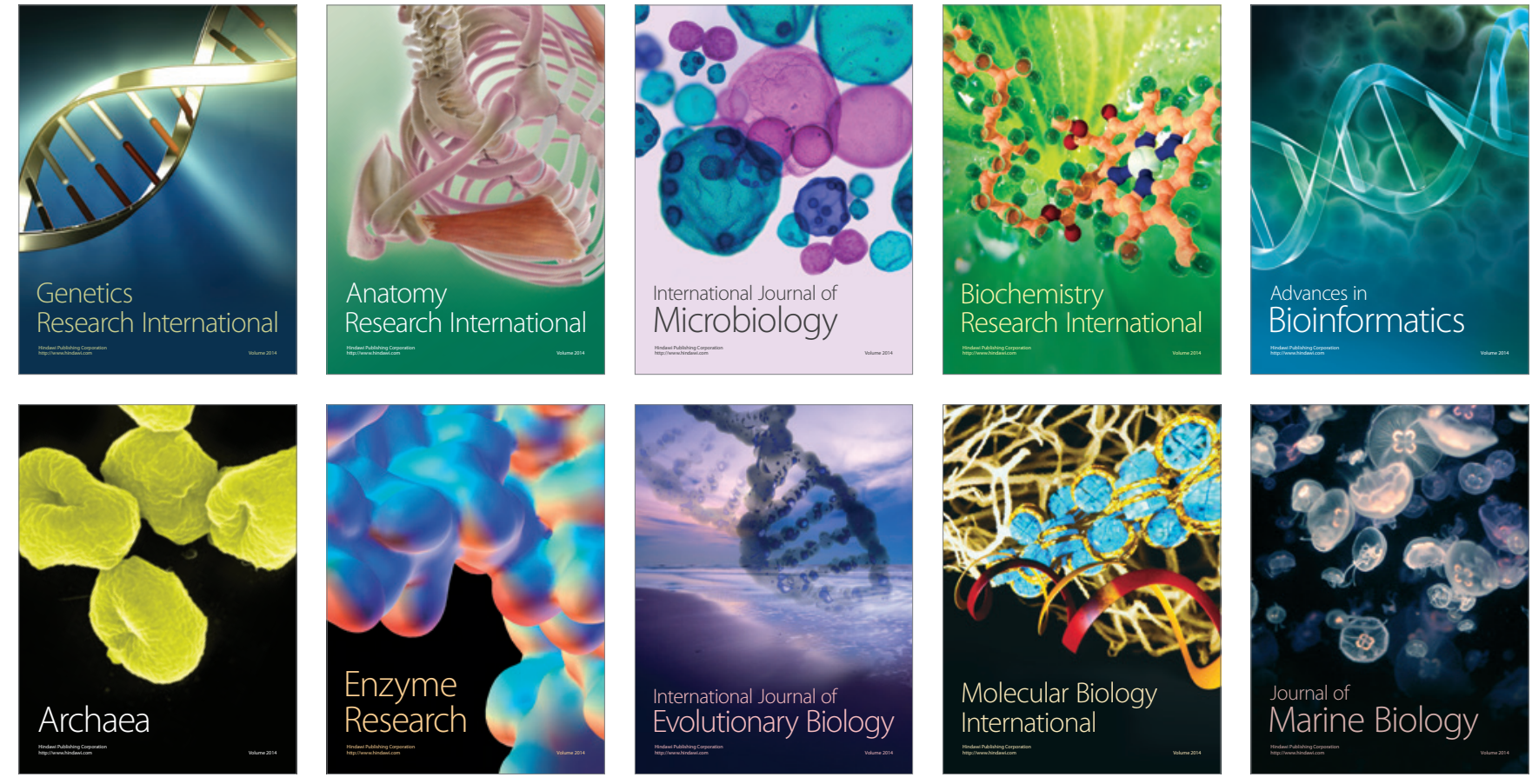